\title{
Mitochondrial therapy for Parkinson's disease: Neuroprotective pharmaconutrition may be disease-modifying
}

This article was published in the following Dove Press journal:

Clinical Pharmacology:Advances and Applications

16 September 2010

Number of times this article has been viewed

\section{Richard Kones \\ Cardiometabolic Research Institute, Houston, TX, USA}

\begin{abstract}
Progressive destruction of neurons that produce dopamine in the basal ganglia of the brain, particularly the substantia nigra, is a hallmark of Parkinson's disease. The syndrome of the Parkinsonian phenotype is caused by many etiologies, involving multiple contributing mechanisms. Characteristic findings are pathologic inclusions called Lewy bodies, which are protein aggregates inside nerve cells. Environmental insults are linked with the disease, and a number of associated genes have also been identified. Neuroinflammation, microglia activation, oxidative stress, and mitochondrial dysfunction are central processes producing nerve damage. In addition, protein misfolding, driven by accumulation and condensation of $\alpha$-synuclein, compounded by inadequate elimination of defective protein through the ubiquitin-proteasome system, promote apoptosis. Current pharmacologic therapy is palliative rather than disease-modifying, and typically becomes unsatisfactory over time. Coenzyme Q10 and creatine, two agents involved in energy production, may be disease-modifying, and able to produce sufficient beneficial pathophysiologic changes in preclinical studies to warrant large studies now in progress. Use of long-chain omega-3 fatty acids and vitamin D in PD are also topics of current interest.
\end{abstract}

Keywords: Parkinson's disease, mitochondria, inflammation, reactive oxygen species, apoptosis, ubiquinone, creatine, polyunsaturated omega-3 fatty acids, vitamin D

\section{Introduction}

Parkinson's disease (PD), the second most common neurodegenerative disease, is a progressive movement disorder marked by rest tremor, slow muscle movement (bradykinesia), rigidity of muscles, and postural instability. Although its prevalence in the US is presently about $1 \%-2 \%$ in people over 60 years of age, numbers will rise as the proportion of elderly in the population increases. Most symptoms are due to loss of specific dopamine-releasing neurons in the substantia nigra and pars compacta of the brain. Dopamine replacement helps relieve motor symptoms and as such, is successful as palliative therapy. Progress in treatment has been unsatisfactory, simply because there are no disease-modifying agents that are effective.

Delaying the degeneration of dopaminergic neurons essentially means slowing disease progression. Most recently, there has been intense interest in two agents, ubiquinone, also known as coenzyme Q10 (CoQ10) and creatine, which may have potential disease-modifying properties.

Targeting mitochondrial dysfunction with therapeutic agents in PD and other diseases is relatively new. Because mitochondria are involved in the pathogenesis of many illnesses, the concept is already finding wide application.
Correspondence: Richard Kones MD

Cardiometabolic Research institute, 8181

Fannin St, U3I 4 Houston, TX 77055, USA

Tel +17137909100

Fax+l 7137909292

Email drrkones@comcast.net 


\section{Causes}

A number of etiologies of PD have been identified, ${ }^{1}$ and a complex cascade of interrelated molecular events is beginning to unravel. Because more than one factor may contribute over the protracted course of the illness, the term Parkinson's syndrome may be preferable. Current "causes" include genetic and environmental factors, with common mediating mechanisms of reactive oxygen species (ROS), inflammation, and mitochondrial dysfunction playing a central role. An introductory discussion of factors involved in causes of Parkinson's syndrome helps to place the role of nutrients in perspective.

\section{Genetic factors}

Parkin is a protein that participates in the ubiquitin-protease system, and mutations in the encoding gene, PARK2, are among the genetic causes of PD. Even though about 11 "PARK genes" associated with Parkinson's disease have been identified, and over 570 other genes are known to function abnormally, less than $10 \%$ of PD occurs on a genetic basis. ${ }^{2}$ Among several reported mutations, one in the gene coding for $\alpha$-synuclein results in substitution of an alanine moiety for threonine at the PD-1 focus on chromosome 4q21-q23. ${ }^{3}$ The 140-amino acid residue protein $\alpha$-synuclein, which plays a role in dopamine neurotransmission during its storage in vesicles, ${ }^{4}$ is natively unfolded but normally monomeric and soluble. It may misfold and undergo changes which render it insoluble, and/or oligomerize at high concentrations. Protofibrils, $\beta$-pleated sheets composed of fibrils, are putative cytotoxic intermediates. Aggregation residues of the protein may become deposited in Lewy bodies, which are the cardinal pathologic findings in PD. These bodies also contain products of the ubiquitin-proteasome pathway, a protein disposal system in cells.

\section{Environmental}

Environmental variables account for $90 \%$ of PD cases, with pesticides, herbicides, consumption of well water, and some microbes implicated in PD. ${ }^{5,6}$ Maneb and paraquat are pesticides that are particularly troublesome. ${ }^{7}$ Rural residence and agricultural occupation is linked to higher risk. Manganese exposure may speed progression of PD. ${ }^{8}$ While it has been amply demonstrated that non-heme iron raises the PD risk by up to $30 \%,{ }^{9}$ ferritin within the neuromelanin granules of the substantia nigra and ferrous ion may lead to necrosis of cells. ${ }^{10,11}$

\section{Mitochondrial dysfunction}

The current view of mitochondria has changed significantly from the older view of simple high-energy phosphate bond synthesis. The electron transport chain within the inner mitochondrial membrane essentially transfers electrons in food to oxygen, capturing and storing energy in adenosine triphosphate (ATP). In so doing, ROS are released as a proton gradient is created across the mitochondrial membrane. Mitochondria are both a source and a sink for ROS. CoQ10 (ubiquinone) is an essential component of three of four mitochondrial complexes along the electron transport chain and is also a potent antioxidant. Mitochondrial DNA transcription, and subsequently oxidative phosphorylation, may be regulated by the cell's physiologic needs. Conversely, mitochondria participate in several signaling loops that control transcription and cellular DNA transcription. The interaction between genetic and epigenetic signaling and mitochondria is complex. Apoptosis, or programmed cell death, follows a sudden event called mitochondrial permeability transition (MPT), when opening of transition pores allows the passage of larger molecules through the mitochondrial membrane. Hence, they are called the "gates of survival".

Considerable evidence now links mitochondrial dysfunction and $\mathrm{PD}$, partially unifying the different "causes" proposed. One hypothesis is that a selective defect in complex I of the electron transport chain in the mitochondria of cells in the substantia nigra, involving functionally impaired and misassembled subunits, may lead to an apoptotic cascade and PD. ${ }^{12}$ Properties of maternal polymorphic mitochondrial DNA may contribute to an age-related decline in mitochondrial dysfunction, ${ }^{13}$ and complex analysis of mitochondrial genetics further supports this notion. ${ }^{14}$ An imbalance of mitochondrial fission and fusion, ${ }^{15}$ or even poor remodeling of the inner membrane, may contribute to the disease process. ${ }^{16}$ Recently, work using multinuclear magnetic resonance spectroscopy in PD reveals metabolic changes consistent with mitochondrial dysfunction. ${ }^{17}$

In evaluating both nutritional therapeutic changes and pharmacologic agents, studies are hampered by the sporadic nature of PD, which mandate large numbers of patients for statistical significance. In addition, the nutrients involved are not patentable, which requires special funding for trials. Fortunately, encouraging preliminary reports have led to support of two large Phase III trials involving CoQ10 and creatine by the National Institutes of Health in the US.

\section{Inflammation}

Complement activation and raised secretion of proinflammatory cytokines and chemokines have suggested that inflammation is involved in the pathogenesis of PD. ${ }^{18,19}$ Brain microglia are immune phagocytic cells that are activated early 
in the development of PD. These cells mediate innate immune responses, function as scavenger cells, express cytokines, and modulate histocompatibility genes. Tumor necrosis factor- $\alpha$, interleukins (IL) $1 \beta, 6,2$, and 4 , prostaglandins $\left(\mathrm{E}_{2}, \mathrm{~J}_{2}\right)$, nitric oxide, inducible nitric oxide synthase, and other molecules released from immune and dying cells mediate the demise of cells in the substantia nigra which release dopamine. Neuroinflammation, now the basis for recent models of PD, ${ }^{20,21}$ remains an attractive therapeutic target. ${ }^{22}$

\section{Reactive oxygen species}

Oxidative stress exists when the amounts of ROS and reactive nitrogen species (RNS), such as peroxynitrites, exceed the antioxidant mechanisms that are available in the body. The source of these molecules is primarily from activated inflammatory and immune cells, specifically from microglial nicotinamide adenine dinucleotide phosphate (NADPH) oxidase activity and mitochondria. Phagocytic NADPH oxidase (NOX) comprises at least six components, ie, the plasma membrane-spanning cytochrome b558 (composed of gp91phox and p22phox), three cytosolic components (p67phox, p47phox, and p40phox), and rac, a small G protein. Experimental models of PD suggest that NOX is responsible for nerve cell degeneration. ${ }^{23}$ Preclinical models of PD confirm that such hyperreactive molecules are linked with the death of dopaminergic cells. ${ }^{24}$ ROS also amplify the release of cytokines, such as tumor necrosis factor- $\alpha$, to increase nerve cell destruction. Mitochondrial antioxidants have been of intense investigative interes $\mathrm{t}^{25}$ to thwart this destructive pathway. The relationships between mitochondrial dysfunction, the vulnerability of substantial nigra cells to stressors, and L-type $\mathrm{Ca}_{\mathrm{v}} 1.3 \mathrm{Ca}^{2+}$ channels that drive their rhythmic pacemaking activity ${ }^{26,27}$ are unknown.

\section{Protein accumulation}

Cellular control of protein quality involves removal of abnormal proteins by the ubiquitin-proteasome system and prevents protein accumulation from damaging the cell. ${ }^{28}$ The classic example, $\alpha$-synuclein- and ubiquitin-positive inclusion bodies, are the pathologic hallmarks of PD, and a defective ubiquitin-protease system has been thought to contribute to their accumulation. Proteasomal degradation through the ubiquination-protease system produces polyubiquinated proteins, whereas ubiquitinated $\alpha$-synuclein found in Lewy bodies in surviving substantia nigra nerve cells are mono- and diubiquitinated forms. ${ }^{24}$ Such proteins may result from environmental factors and toxins, genetic mutations, and errors in transcription, translation, and/or protein folding. Misfolding of proteins and failure to remove defective proteins are intimately associated with the pathogenesis of PD. The ubiquitin-proteasome pathway may be overwhelmed or malfunction in PD. ${ }^{29}$ Excessive amounts of aggregated and changed forms of $\alpha$-synuclein also raise levels of ROS and participate in mitochondrial dysfunction. ${ }^{30}$ Promotion of correct protein folding and facilitating removal of harmful proteins with agents such as heat shock proteins are potentially fertile areas for future investigation.

\section{Excitotoxicity}

Microglia, once activated, secrete another class of neurotoxic agents, ie, excitotoxins, which overstimulate the receptors for glutamate, an excitatory neurotransmitter, allowing excessive amounts of calcium to enter nerve cells. Glutamate accumulation promotes development of RNS, calcium-mediated mitochondrial damage, and resulting apoptosis in neurons.

The etiologies, mechanisms of pathogenesis in dopaminergic cell death, and potential therapeutic targets are summarized in Table 1.

\section{Creatine}

Creatine, chemically known as $\alpha$-methyl-guanidinoacetic acid, is a naturally occurring nitrogenous organic acid which is produced endogenously, and is also ingested in food. About half of total body creatine is derived from dietary meat, with the remainder synthesized in the liver and pancreas from glycine, methionine, arginine, and two enzymes. Since these two enzymes are not concentrated within the same organ, synthesis begins in the kidney and is completed by methylation in the liver. The largest amount of creatine is found in skeletal muscle, followed by cardiac muscle, and these are tissues that do not synthesize creatine significantly. Regulation of endogenous synthesis most likely occurs at a pretranslational level. ${ }^{31}$ Creatine synthesis may be a more significant process than previously believed, with an important influence upon amino acid metabolism. ${ }^{32,33}$ Because of the intermetabolic involvement of methionine and homocysteine, methyl donor balance is also affected..$^{33}$ Approximately $1.7 \%$ of the total creatine pool is excreted daily in the form of urinary creatinine.

Well known because it is used as an ergogenic aid by athletes and bodybuilders to increase strength and muscle mass, creatine is not only a storage depot of energy, ${ }^{34}$ but may also facilitate recovery after exercise ${ }^{35,36}$ and promote muscle repair. ${ }^{36}$ The reaction of primary interest in which creatine participates is phosphorylation by the enzyme creatine kinase to form phosphocreatine in mitochondria (Figure 1).

Since the reaction is reversible, phosphocreatine serves as an energy buffer when high-energy phosphate is needed. 
Table I Summary of factors and approaches in the pathogenesis of Parkinson's disease

\begin{tabular}{|c|c|}
\hline \multirow[t]{3}{*}{ Etiology } & Genetic \\
\hline & Environmental \\
\hline & Genetic susceptibility to environmental factors \\
\hline \multirow[t]{6}{*}{ Mechanisms in pathogenesis } & Inflammation \\
\hline & Mitochondrial dysfunction \\
\hline & Oxidative and nitrosative stress \\
\hline & Accumulation of proteins/defective protein clearance \\
\hline & Excitotoxicity \\
\hline & Loss of neurotrophic factors \\
\hline \multirow[t]{5}{*}{ Mechanisms of dopaminergic cell death } & Loss of mitochondrial membrane potential \\
\hline & Mitochondrial permeability transition \\
\hline & Loss of cytochrome c from mitochondria \\
\hline & Accumulation of cytosolic calcium \\
\hline & Activation of apoptotic pathways \\
\hline \multirow[t]{6}{*}{ Therapeutic classifications and potential targets } & Anti-inflammatory \\
\hline & Mitochondrial (coenzyme QI0, Carnitine, uncoupling protein 2 expression) \\
\hline & Excitotoxicity (antiglutamate) \\
\hline & Calcium overload (calcium channel blockers) \\
\hline & Protein accumulation (heat shock proteins, proteasomal enhancers) \\
\hline & Antiapoptotic stabilizers \\
\hline
\end{tabular}

In addition, creatine/phosphocreatine facilitates energy transfer by diffusing from mitochondria, where ATP is synthesized, to other cellular locations where ATP is utilized, and stabilizes ATP synthesis. Creatine also modulates the adenosine diphosphate (ADP) ATP ratio, so ATPase function is not unduly inhibited. The supportive action of creatine on energy transduction has led to its hypothetical role as an indirect antioxidant in preventing mitochondrial permeability transition..$^{27,38}$

A transporter is responsible for creatine uptake into muscle, kidney, and brain, and appears to be a member of the sodiumdependent neurotransmitter transporter family. Transportation occurs against a substantial creatine gradient and is driven by sodium-potassium-ATPase. ${ }^{39}$ Creatine is not synthesized in the brain, but is made in glial cells. Neurons receive creatine slowly from nearby glia and from the blood via the creatine transporter. The function of a creatine transporter in mitochondrial membranes has not been well characterized.

Creatine not only increases muscle strength in healthy athletes, but may also do so when muscle strength is reduced as a result of disease. In both preclinical studies and in patients, oral creatine has been shown to increase strength in neuromuscular disorders, ${ }^{40}$ including the muscular dystrophies. ${ }^{41}$ Beneficial effects on muscular strength has also been reported in patients with heart failure, ${ }^{42,43}$ and in the elderly suffering from sarcopenia, ${ }^{44,45}$ ie, loss of muscle mass in which both inflammation and mitochondrial dysfunction are evident. Muscle mass and strength lost during immobilization may also be preserved by creatine administration. ${ }^{46}$

\section{Creatine effect on cognition and neuroprotection}

The important role creatine plays in energy metabolism in nerve tissue and brain physiology is less well appreciated than its muscular effects. Severe brain creatine/phosphocreatine deficiency resulting from an inborn error of metabolism is characterized by mental retardation, striking language impairment, autistic-like behavior, movement disorders, and/or seizures. ${ }^{47,48}$ Such syndromes are partially reversible with creatine replacement therapy.
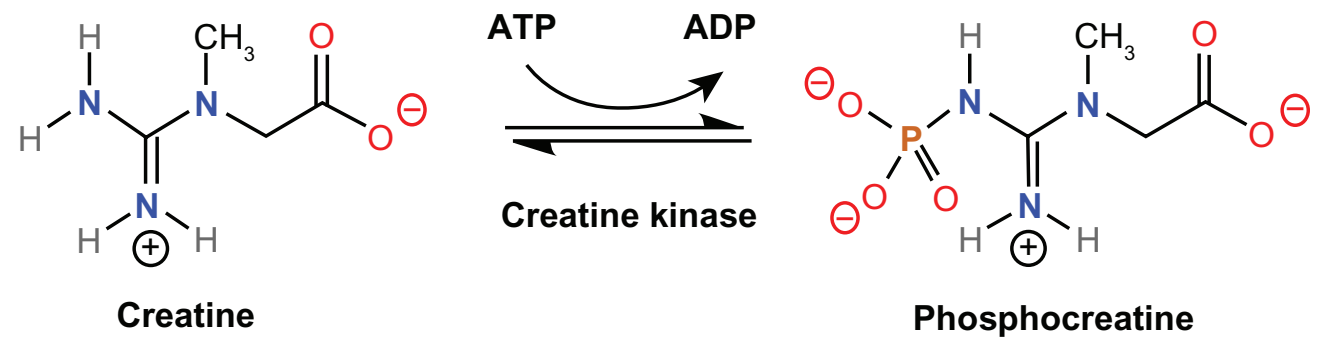

Phosphocreatine

Figure I Phosphorylation of creatine by creatine kinase to form phosphocreatine in mitochondria. 
Due to a relative lack of dietary meat, vegetarians and vegans generally have low creatine intakes. A double-blind, placebo-controlled, crossover trial in 45 such individuals was conducted by supplementing with creatine monohydrate $5 \mathrm{~g} /$ day. Creatine was found to improve nonverbal intelligence, verbal memory capacity, and short-term memory. ${ }^{49}$

Sleep deprivation has a negative effect upon cognition, psychomotor performance, and mood, and is in part due to depletion of brain creatine. ${ }^{50}$ In a double-blind study of 19 sleep-deprived subjects, tests of random movement generation, verbal and spatial recall, choice reaction time, static balance, and mood state were done with and without administration of creatine $20 \mathrm{~g}$ /day, during progressively greater sleep deprivation. After sleep deprivation for 24 hours, creatine had a positive effect on mood state and tasks that placed a heavy demand on the prefrontal cortex. ${ }^{50}$ Further work by the same group extended and confirmed similar improvement in multiple tests of cognitive function using creatine $20 \mathrm{~g} /$ day in the elderly. ${ }^{51}$

In laboratory models of spinal cord injury, ${ }^{52,53}$ and after experimental traumatic brain injury, ${ }^{54}$ creatine either protected against cell damage or assisted in recovery. Similarly, creatine affords protection in mouse models of stroke. ${ }^{55,56}$ In one study, creatine supplementation for three weeks followed by a 45-minute ligation of the middle cerebral artery reduced the amount of brain tissue lost by about $40 \%{ }^{57}$ No significant changes in creatine/phosphocreatine were identified. In other preparations, however, creatine was capable of attenuating decreases in energy-containing phosphocreatine and ATP in anoxic brain tissue, and reduced nerve damage caused by excitotoxins and malonate. ${ }^{58}$

Creatine is also neuroprotective in animal models of amyotrophic lateral sclerosis ${ }^{59}$ and in Huntington's disease. ${ }^{60}$ Benefits of creatine in human patients, ${ }^{61}$ including reductions in markers of oxidative injury to DNA, ${ }^{62}$ have been sufficient to warrant a Phase III trial sponsored by the National Institutes of Health. Huntington's disease is an incurable neurodegenerative disease in which there is abnormal movement and marked loss of nerve cells. Huntington's disease shares pathogenetic similarities with $\mathrm{PD}$, including aberrant protein deposition, oxidative damage, and mitochondrial dysfunction, all in association with an intracellular energy crisis.

Taken together, the selected studies mentioned above indicate creatine is capable of neuroprotection in a variety of situations in which either depletion of phosphocreatine or metabolic stress produces nerve cell death.

A rodent model of PD is produced by using 1-methyl 4-phenyl 1,2,3,6-tetrahydropyridine (MPTP), which produces a loss of about $30 \%$ of the cells that secrete dopamine in the substantia nigra. In this model, creatine protects against both neuron and dopamine loss in a dose-dependent manner. ${ }^{58,63}$

Some recent basic science correlates of these observations help us to understand and unite the actions of different agents into a cohesive working model. First, creatine has direct antioxidant actions against both reactive oxygen and nitrogen species, including the destructive superoxide and peroxynitrite moieties. ${ }^{64}$ Given the critical role of oxidative stress in producing neurodegeneration in PD and related conditions, the antioxidant effects of creatine may be a mechanism of action, ${ }^{59}$ but what is a cause and what is an effect remains unknown. ${ }^{65}$

Second, unique subcellular spatial locations of mitochondrial creatine kinase have been described that expand our understanding of the role of the creatine/phosphocreatinecreatine kinase system. Mitochondria have inner and outer membranes which make contact at discrete points. ${ }^{66}$ It is believed that a "microcompartment" exists at those points ensuring that, if creatine is available, ATP efficiently converts to phosphocreatine. ${ }^{37,67}$ The resulting high concentration of ADP helps stabilize mitochondrial transition pores, decreasing the probability of MPT and cell death.

This action is important because a number of other coexisting factors tend to raise the probability of MPT, including loss of CoQ10 from the electron transport chain, sluggish oxidative phosphorylation, loss of mitochondrial membrane potential, oxidative stress, and increased calcium flux. MPT may be accompanied by further loss of membrane potential and leakage of proapoptotic molecules, such as cytochrome c, out of the mitochondria. One apoptotic cascade involves members of the Bcl-2 family, proteins that are either pro- or antiapoptotic, with consequent activation of caspases that trigger apoptosis and subsequent cell death. ${ }^{68,69}$ Phosphocreatine also functions to ensure sufficient energy so calcium pumps may prevent local rises in calcium concentrations, which may itself promote apoptosis. ${ }^{70}$ One can easily appreciate how delicate the balance of multiple forces upon mitochondria may be, ultimately determining the fate of vulnerable nerve cells which are critical in the production of dopamine. While it has been thought that many of the salutary effects of creatine are related to energy transduction, a component may in fact be energy-independent. ${ }^{71}$

\section{Phase II and Phase III studies}

After a small initial trial of creatine in PD patients established its safety, a randomized double-blind, Phase II futility study assessed the effect of creatine $10 \mathrm{~g}$ /day and minocycline 
on the clinical course of early PD. ${ }^{72}$ In this study, using a predetermined "futility" threshold, creatine lowered the total Unified Parkinson's Disease Rating Scale (UPDRS) score from the onset of treatment to 12 months or when standard medical therapy was needed (whichever came first). The futility threshold assigned was a $30 \%$ reduction in UPDRS score progression, taken from the control group of the Deprenyl and Tocopherol Antioxidative Therapy of Parkinsonism (DATATOP) trial. ${ }^{73}$ Creatine could not be rejected as futile based upon the UPDRS score needed to qualify, and was tolerated well. After a year, PD progression was delayed by nearly $50 \%$, as judged by UPDRS scores. ${ }^{72}$

Following this, the National Institute of Neurological Disorders and Stroke announced a Phase III clinical trial randomizing 1720 early-stage PD patients to creatine $10 \mathrm{~g}$ /day or placebo. ${ }^{74,75}$ The study will last about $5-7$ years and be conducted at 52 medical facilities.

Creatine is well absorbed, bioavailable, and safe. In one study, a creatine dose of $20 \mathrm{~g} /$ day was given to PD patients along with resistance training. ${ }^{76}$ Muscular endurance and upper body strength improved. Side effects of creatine include gastrointestinal symptoms, muscle cramps, and an increase in intracellular water because of the osmotic load imposed by additional creatine.

\section{Coenzyme Q10 (ubiquinone)}

CoQ10 (ubiquinone) is a lipid-soluble benzoquinol with a side chain of 10 isoprenoid units (Figure 2). Of the total CoQ10 plasma pool, $60 \%$ is endogenous, ${ }^{77}$ and the remainder comes from ingested CoQ10 or its precursors. In vivo, about $95 \%$ is found as the reduced form, ie, ubiquinol. CoQ10 is best known for its role in the inner mitochondrial membrane that shuttles electrons in the electron transport chain from complexes I and II to complex III (Figure 3). ${ }^{78}$

Because of its relatively small size, CoQ10 is able to diffuse within the lipid bilayer of the inner mitochondrial membrane between fixed electron carriers. It is therefore essential for oxidative phosphorylation, and suboptimal CoQ10 concentrations within the respiratory chain complexes impede the development of a protein gradient across the mitochondrial inner membrane, resulting in defective production of ATP. Intramembrane CoQ10 levels are therefore rate-limiting. CoQ10 deficiency also predisposes to MPT, leading to apoptosis. It also serves as a cofactor for uncoupling proteins and other mitochondrial dehydrogenases, as a regulator of extracellularly-induced ceramide-dependent apoptotic pathways,$^{79}$ and as a regulator of the MPT pore. CoQ10 is also an effective antioxidant

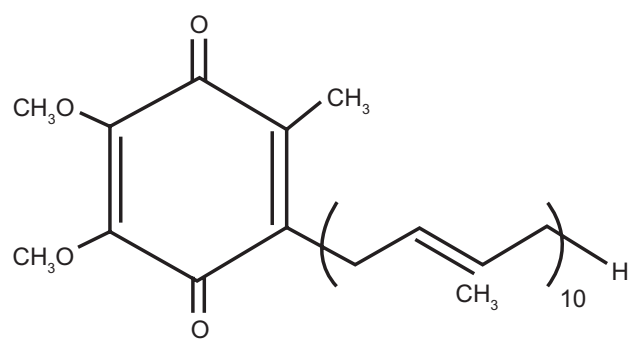

Ubiquinone (2,3-Dimethoxy-5-methyl-6-decaprenyl-1,4-benzoquinone)

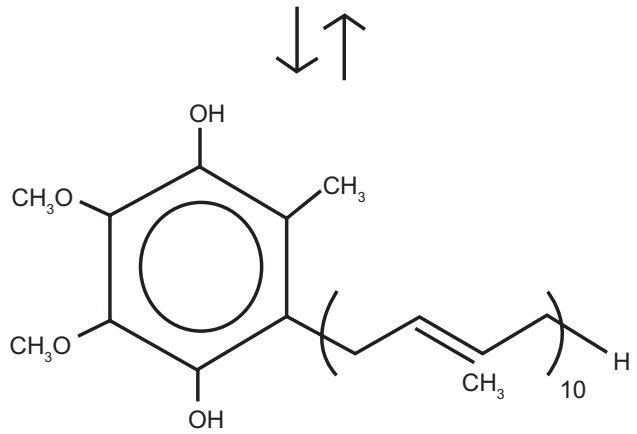

Ubiquinol (2,3-Dimethoxy-5-methyl-6-decaprenyl-1,4-benzoquinol)

Figure 2 The structures of ubiquinone (top) and ubiquinol (bottom). Ubiquinone, the oxidized (benzoquinone form of the pair, is 2,3-dimethoxy-5-methyl-6-decaprenylI,4-benzoquinone. Its isoprenoid group $\left(\mathrm{CH}_{3}-\mathrm{CH}=\mathrm{C}\left(\mathrm{CH}_{3}\right)-\mathrm{CH}_{3}\right)$ is repeated $\mathrm{I} 0$ times in the side chain. Ubiquinol, the reduced (hydroxyl groups at positions I and 4 on the benzene ring) form, less two electrons, is 2,3 dimethoxy-5-methyl-6-decaprenylI,4-benzohydroquinol.

that is a free radical scavenger in intracellular organelle membranes, and is an important antioxidant that travels in lipoproteins, affording partial protection against oxidation of low-density lipoprotein. ${ }^{80} \mathrm{CoQ} 10$ levels decrease with age, in chronic disease, and as a side effect of certain pharmacologic agents, especially statins.

Evidence implicating mitochondrial dysfunction in $\mathrm{PD}$ is now undeniable. ${ }^{14,17,81}$ As mentioned, MTPT is toxic to complex I in the mitochondria and mimics Parkinson's syndrome in several species, including man. ${ }^{82}$ Rotenone, a pesticide and neurotoxin, also inhibits complex $\mathrm{I}^{83}$ It has been implicated in PD cases and interestingly, activates microglia, leading to destruction of those neurons that produce dopamine..$^{84,85}$

Platelet mitochondria in untreated PD patients show low complex I and II/III activity, ${ }^{86}$ and complex I activity is also low in the substantia nigra of PD patients..$^{87} \mathrm{~A}$ novel method of studying complex I activity and apoptosis in mitochondria from PD patients confirmed that complex I is indeed depressed, in association with lower ATP and cytochrome c concentrations, depolarization of membranes, and greater caspase 3 activity, a key step in one apoptotic pathway. ${ }^{88}$ Hence, in this preparation, defective oxidative phosphorylation resulting from complex I pathology appears to be linked to enhancement of apoptotic pathways in PD. 


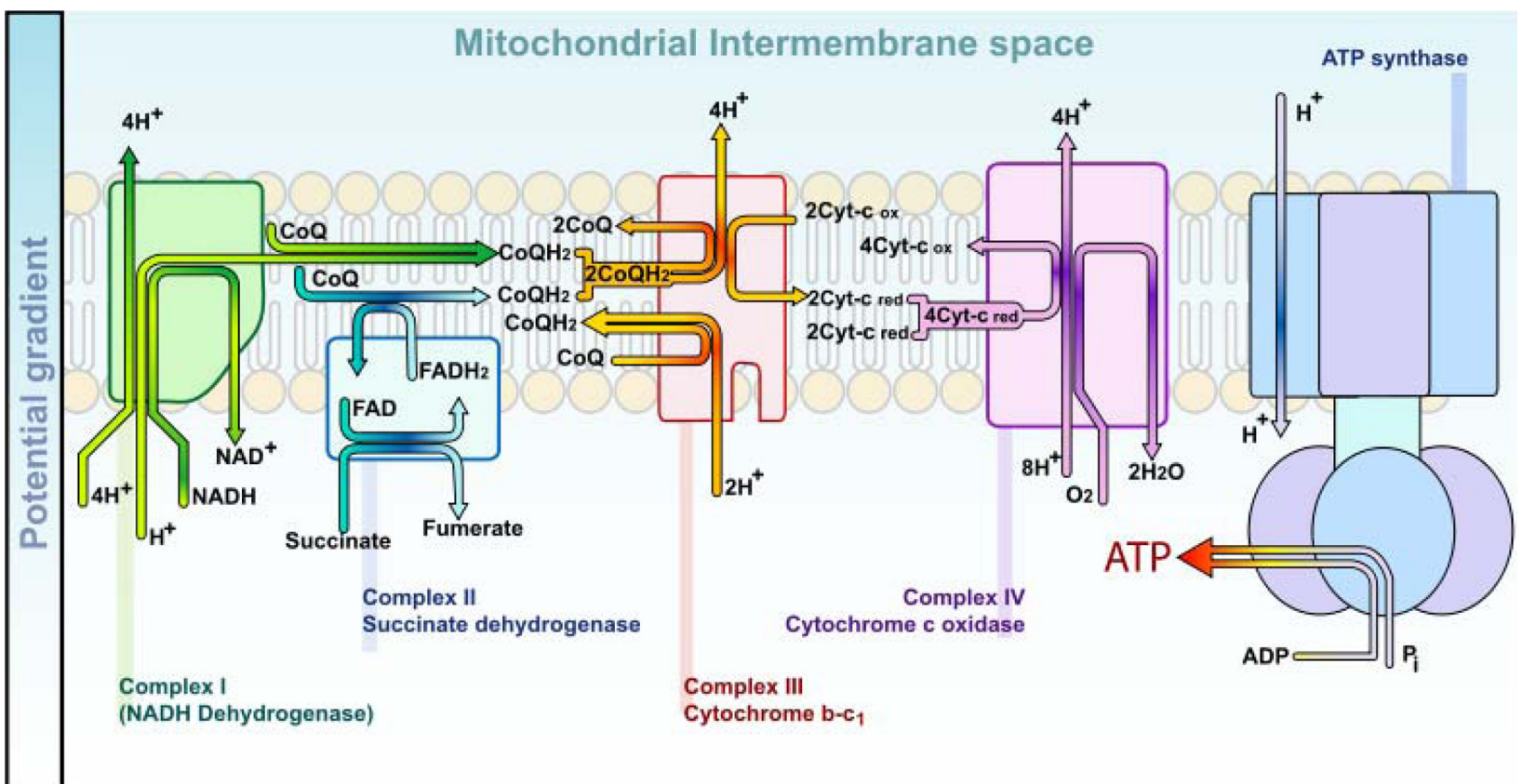

Figure 3 Electrons move from food to Krebs cycle intermediates, in a series of oxidation-reduction reactions as they are shuttled through complexes I through IV of the respiratory chain, eventually reaching oxygen. The electron transport chain effecting oxidative phosphorylation is composed of fixed multimeric protein complexes I through $\mathrm{V}$, each with multiple subunits, along the inner mitochondrial membrane, along with two electron carriers, ie, ubiquinone and cytochrome c. As electrons move along the oxidation-reduction complexes I-IV, protons are pumped from the matrix to the intermembrane space by complexes I, III, and IV, creating a proton [ $\mathrm{H}^{+}$] gradient across the mitochondrial inner membrane. As the protons return to the intermembrane space through complex $V$ (far right, labeled ATP synthase), dissipating the gradient, changes in conformations of enzyme $\mathrm{F}_{1} \mathrm{~F}_{0}$ ATP synthase, which spans the membrane, produce ATP. The inner mitochondrial membrane must remain impermeable to [ $\left.\mathrm{H}^{+}\right]$in order to sustain the gradient, which uses about $15 \%$ of the total metabolic rate of working tissue.

Reproduced with permission of Mariana Ruiz Villarreal, via Wikipedia commons.

Abbreviations: CoQ, Coenzyme QI0 (ubiquinone); CoQH, reduced Coenzyme QI0 (ubiquinol); NAD, nicotinamide adenine dinucleotide; AT, adenosine triphosphate; $A D$, adenosine diphosphate; Cyt c, cytochrome c.

CoQ10 levels are nearly one-third lower in platelet mitochondria from PD patients than in age- and gendermatched controls, and levels in serum and some organs fall faster in PD patients during aging as well. ${ }^{89}$ Furthermore, the proportion of CoQ10 in its oxidized form is higher in PD patients, linking oxidative stress with disease pathogenesis.

Orally administered CoQ10 reduced the loss of dopamine and the nerves that produce it in the substantia nigra of MTPT-treated mice..$^{90} \mathrm{CoQ} 10$ is neuroprotective against damage mediated by malate and excitotoxins. ${ }^{91,92}$ Rotenoneinduced loss of dopaminergic neurons is also attenuated by CoQ10 pretreatment. ${ }^{93,94}$ As a result of findings in a primate model of PD, activation of uncoupling protein 2, leading to preservation of mitochondrial membrane potential and ATP production, was postulated to be one mechanism of CoQ10 protection. ${ }^{95}$ However, binding sites for CoQ10 that regulate the permeability transition pore have been identified within complex I in mitochondria, and therefore protection may also be afforded in PD because of the antiapoptotic effect of MPT pore stabilization.

Studies using magnetic resonance spectroscopy have documented raised cerebral lactate levels and metabolic changes that suggest depressed aerobic and greater anaerobic metabolism in PD patients. ${ }^{17,96}$ Using anatomic magnetic resonance imaging combined with phosphorus and proton magnetic resonance spectroscopic imaging, low levels of both ATP and phosphocreatine in the midbrain of PD patients were found ${ }^{97}$ This constitutes hard evidence in vivo that mitochondrial dysfunction and defective oxidative phosphorylation are involved in $\mathrm{PD}$.

An early study of CoQ10 administration to patients produced no symptomatic improvement but did raise complex I activity. ${ }^{98} \mathrm{~A}$ Phase II study (QE2) to evaluate safety and tolerability, but not neuroprotection or efficacy, of CoQ10 300-1200 mg was undertaken in 80 PD patients. ${ }^{99}$ There was a statistically meaningful difference between those receiving $1200 \mathrm{mg}$ and $300 \mathrm{mg}$, as measured by the UPDRS. Slower deterioration was noted in all three sections of the UPDRS (Part 1, mentation, behavior and mood; Part 2, activities of daily living; and Part 3, motor examination). The higher dose of CoQ10 produced greater activity of the electron transport chain.

A futility trial using CoQ10 $2400 \mathrm{mg}$ randomized 71 patients with early untreated PD for one year. The mean change in UPDRS, compared with a prespecified threshold 
from the DATATOP trial, was not found to be futile, and the authors concluded more research was warranted. ${ }^{100}$

Currently a Phase III efficacy (QE3) trial is randomizing about 600 untreated patients to CoQ10 $120 \mathrm{mg} /$ day or $2400 \mathrm{mg} /$ day or placebo. Using the three parts of the UPDRS and other scales, function, cognition, and quality of life will be followed for 16 months and/or when symptomatic therapy becomes necessary. Plasma CoQ10 levels at months 1, 8, and 16 are included in the protocol. ${ }^{101}$

The number of $\mathrm{CoQ} 10$ products and processing efforts to increase CoQ10 absorption is bewildering, and the ability of products to raise CoQ10 levels varies considerably. Ubiquinone has been supplied in various forms, characteristically with poor absorption. Ubiquinol, the oxidized form, and/or solubilized forms, are better absorbed and are preferred when older or ill populations are being treated. Monitoring CoQ10 levels is desirable to assure adequate blood levels, since the large amounts of CoQ10 prescribed and the expense may impair adherence.

\section{Long-chain omega-3 polyunsaturated fatty acids}

Due to both overconsumption of omega- 6 fats and underconsumption of omega-3 fats, the typical Western diet contains an omega-6/omega- 3 ratio of about $20: 1$, with the ideal estimated between 1-3:1. This is unfortunate, given that a higher intake of omega-3 polyunsaturated fatty acids (PUFA) is associated with low all-cause mortality. ${ }^{102}$ Omega- 3 fats constitute over $50 \%$ of brain weight. Of the two major active PUFA, eicosapentaenoic acid (EPA) is regarded as the more antiinflammatory, with docosahexaenoic acid (DHA) more likely to be incorporated into membranes and act through derivatives called resolvins and neuroprotectins. While the recommended amount of DHA is about $200-300 \mathrm{mg} /$ day, the typical intake ranges from $60-80 \mathrm{mg} /$ day. Up to $60 \%$ of the fatty acids esterified in neuronal membrane phospholipid are DHA. In the elderly, total intake of omega-3 PUFA is generally poor, ${ }^{103}$ while robust consumption is associated with improved cognitive function. ${ }^{104-107}$

Epidemiologic studies suggest that high intake of omega-3 PUFA may reduce the risk of PD, while acute studies in animal models of PD also suggest a more immediate neuroprotective effect. In the Rotterdam study, over 5000 subjects completed a food frequency questionnaire and were followed for six years. ${ }^{108}$ Both dietary omega-3 PUFA and monounsaturated fatty acids were associated with a significantly reduced risk of PD. No link was noted with either omega-6 PUFA or DHA intake.
In two other large prospective studies, there was no association between omega-3 PUFA and PD risk. ${ }^{109}$ However, when total PUFA in the diet was replaced isocalorically with saturated fat, the risk of PD rose. A recent analysis of diet in the same cohort showed an inverse association of PD risk with intake of fish, fruit, and vegetables. ${ }^{110}$

In monkeys who received MPTP to induce PD-type lesions, DHA was found to protect against dyskinesias (abnormal movements) induced by levodopa. ${ }^{111}$ In fact, DHA appeared to lower the severity, or delay the appearance of the motor movements arising as complications of levodopa therapy. These results are important because they indicate omega-3 PUFA are capable of potentially modifying the course of the pathogenesis of complications of an animal equivalent of $\mathrm{PD}$.

In a mouse model of PD, animals were maintained on either a control diet, conventionally high in omega- 6 fats, or another diet high in omega-3 fats, followed by administration of MPTP. ${ }^{112,113}$ In the high omega-3 diet group, mice suffered no loss of dopamine or dopaminergic neuron death after MPTP was given. In contrast, mice consuming the "control" (Western) diet manifested loss of nigral nerve cells that produce dopamine, with dopamine secretion decreased by half. This study clearly shows that high omega-3 PUFA has a powerful neuroprotective effect in the murine model of PD.

MPTP, after injection, may lead to activation of microglia, with a consequent rise in interleukins $1 \beta$ and 6. Deletion of COX-2 enzymes, or pharmacologic inhibition of COX-2, diminishes MPTP toxicity, supporting a strong inflammatory component in the events involved in the MPTP-induced damage typical of PD. Indeed, some authors have hypothesized that DHA incorporates into and displaces proinflammatory omega- 6 fats in neurons and mitochondria of the substantia nigra $^{114}$ to attenuate the harmful actions of MPTP. Quelling of oxidative and mitochondrial DNA damage by DHA is postulated as another mechanism. ${ }^{115}$ DHA also changes membrane structure, ${ }^{116}$ signal transduction, ${ }^{117}$ and voltage-dependent calcium channels in nerves, ${ }^{118}$ which is of particular interest in view of the calcium channel-related hypothesis concerning destruction of neurons in PD. ${ }^{27}$ Last, DHA modulates intracellular calcium and may protect against caspase-mediated apoptosis. ${ }^{119}$ The mechanisms of these protective effects in laboratory models are noteworthy, because they parallel those operative in the human clinical syndrome.

Omega-3 PUFA modulate inflammation, ${ }^{116,120}$ may inhibit generation of ROS, ${ }^{121}$ and modify signaling in lipid rafts. ${ }^{106}$ DHA in membranes are released by phospholipase, and derivative molecules such as neuroprotectin D1 have 
pleiotropic neurotrophic properties, including promotion of antiapoptotic proteins in the Bcl-2 family, as well as potent anti-inflammatory actions. Another property of potential significance in PD, in which protein misfolding has been the subject of intense interest, is the ability of neuroprotectin D1 to prevent misfolding and forestall cell death. ${ }^{122}$ The multimechanistic neuroprotection afforded by DHA has only recently been appreciated in the biology of neurodegenerative diseases.

Inefficient metabolic pathways exist for elongation of the 18 -carbon $\alpha$-linolenic acid to EPA and DHA. In older adults, conversion of $\alpha$-linolenic acid to DHA is quite limited, with better yields for EPA. ${ }^{123}$ There is doubt that conversion, occurring chiefly in the liver, under the best of circumstances, can alone furnish sufficient DHA for optimal neurologic health. ${ }^{124}$ Therefore, these omega-3 PUFA requirements should be met by using the long chains themselves, EPA and DHA, rather than through plant sources rich in $\alpha$-linolenic acid, the most popular being flax.

\section{Vitamin D}

Calcitriol (1,25-dihydroxyvitamin D) is more of a secosteroid hormone than "a vitamin", and vitamin D receptors are plentiful in brain neurons and glia. ${ }^{125}$ As in most tissues, vitamin $\mathrm{D}$ receptors regulate genomic and metabolic signaling in nerve cells. Vitamin D helps control neurotrophin turnover, glutathione synthesis, inducible nitric oxide synthase activity, and apoptosis, all of which are pertinent to the pathogenesis of PD. Vitamin D also has immunomodulatory and neuroprotective effects in brain tissue. The benefit of maintaining optimal vitamin D levels in the elderly receiving home care, or confined to a nursing home, has received considerable recent attention, and is part of a growing realization that vitamin D deficiency is in fact a major public health issue.

A relatively high prevalence of vitamin D deficiency and low bone mass in PD has been known for some time. ${ }^{126}$ In one study, $55 \%$ of patients with PD, $41 \%$ with Alzheimer's, and $36 \%$ of controls were vitamin $\mathrm{D}$ deficient, with more PD patients being markedly deficient. ${ }^{127}$ Moreover, cognitive function, impaired in about $40 \%$ of PD patients, is dependent upon adequate vitamin D levels in older men. ${ }^{128}$ In the elderly receiving home care, vitamin D deficiency (14.5\%) and insufficiency $(44.3 \%)$ were associated with a two-fold risk of dementia, stroke, and large vessel infarcts, suggesting that vitamin D deficiency also contributed to cerebrovascular disease. ${ }^{129}$ The presence of dementia in PD patients is an independent predictor of mortality. ${ }^{130}$
PD patients with low bone mass face an additional risk for fractures compared to their counterparts in the general population. ${ }^{131}$ Several randomized controlled trials have confirmed that vitamin D replacement in PD patients is beneficial, safe, and warranted. ${ }^{132}$ Calcium and vitamin D 5000 IU daily can increase lumbar bone density up to $28 \%$ within a year in association with a lower incidence of fractures. ${ }^{133}$ A minimal amount of supplementary vitamin D 400 IU daily, may lower hip fractures by $18 \%$ and nonvertebral fractures by $20 \% .^{134}$

Sarcopenia, ie, age-related decrease in muscle mass, is another potential consequence of hypovitaminosis D. ${ }^{135}$ Muscle weakness (a prominent feature of severe clinical vitamin D deficiency), substandard physical performance, and increasing debility are predicted by poor vitamin $\mathrm{D}$ status in the elderly. ${ }^{136}$ These may be accompanied by pain, which is another debilitating factor. After treatment with vitamin D, binding of vitamin D to its receptor in muscle leading to de novo protein synthesis are events that occur earlier than vitamin D benefits upon bone. Moreover, vitamin D replacement may reverse such muscle impairment, and assists during rehabilitation to attain better outcomes. ${ }^{137}$ Vitamin D deficiency may cause a skeletal muscle myopathy even without detectable bone involvement. ${ }^{138}$ By directly increasing muscle performance, vitamin D administration improves climbing ability and promotes physical activity. ${ }^{132}$

The constellation of postural instability (a common feature of PD), poor muscle strength, frailty, age-related comorbidities, and confusion create a perfect "storm" for falls in this population. Partial vitamin D replacement at $800 \mathrm{IU} /$ day halves the rate of falls in older residents in facilities, ${ }^{139}$ an effect which qualitatively persists even in latitudes bathed by sunlight. ${ }^{140}$ Each year, one-third of people 65 years or older suffer a fall, with $9 \%$ of them visiting an emergency room and $5 \%-6 \%$ sustaining a fracture. The consequences of falls and hip fractures are dire, with $50 \%$ having permanent functional disabilities, $20 \%$ or more requiring nursing home placement, and up to $20 \%$ dying within a year. Moreover, in the year after a fracture, $30 \%$ are readmitted for acute care.

A meta-analysis of eight randomized controlled trials examined the effect of vitamin D administration among older participants with or without calcium. ${ }^{134}$ At doses of 700-1000 IU of vitamin $\mathrm{D}_{2}$ or $\mathrm{D}_{3}$, the risk of falls decreased by an average of $19 \%$, with the greatest effect of vitamin $\mathrm{D}_{3}$ at $26 \%$. Amounts of less than $700 \mathrm{IU}$, or serum 25-OH-vitamin D levels of $<60 \mathrm{nmol} / \mathrm{L}$ did not lower the risk of falling. While added calcium and physiotherapy are believed to improve outcomes, the effects of ensuring adequate 25-OH-vitamin D 
blood levels at 50-75 nmol/L provides a relatively inexpensive and simple method for potentially substantial rewards.

Forty-five patients living in a Romanian nursing home with a mean vitamin $\mathrm{D}$ level of $28.9 \mathrm{nmol} / \mathrm{L}$ were given vitamin $\mathrm{D}$ $5000 \mathrm{IU}$ and elemental calcium $320 \mathrm{mg}\left(800 \mathrm{mg} \mathrm{CaCO}_{3}\right)$ to assess the effects upon serum vitamin D level, bone density, parathyroid hormone, and fall rate. ${ }^{141}$ After three months, there was a $58 \%$ decline in parathyroid hormone, vitamin $\mathrm{D}$ level exceeded 74 in $92 \%$ of the patients, and at 12 months, the $\mathrm{Z}$ scores for bone mineral density at the lumbar spine and the hip both increased significantly. These data confirm that to improve low bone density, vitamin D blood levels must be at least higher than $72 \mathrm{nmol} / \mathrm{L}$, and that at least $320 \mathrm{mg}$ of elemental calcium must be added to the diet. The $5000 \mathrm{IU}$ dose was found to be safe in this population, with no persisting hypercalcemia or hypercalciuria.

Actual involvement of vitamin $\mathrm{D}$ in the pathogenesis of PD was proposed by Newmark and Newmark. ${ }^{142}$ In the first longitudinal study to evaluate the association between vitamin $\mathrm{D}$ and the risk of PD, Knekt and associates ${ }^{143}$ recently conducted a prospective study of 3,173 men and women as an extension to the Mini-Finland Health Survey. The enrollees, free from the disease at the beginning of the survey, were followed for 29 years for the development of PD. Investigators found a significant association between levels of serum 25-hydroxyvitamin D levels and the risk of developing PD after adjustment for sex, age, education, alcohol consumption, physical activity, smoking and body mass index. Those with the highest vitamin levels (50 nmol/L) were $65 \%$ less likely to develop PD than those with the lowest levels $(25 \mathrm{nmol} / \mathrm{L})$. Even though the subjects were chronically deficient in vitamin $\mathrm{D}$, since Finland has relatively low exposure to ultraviolet radiation, a dose-response relationship was still evident. In an accompanying editorial, Evatt ${ }^{144}$ discussed the supporting neurobiology of vitamin $D$, especially the finding of 1- $\alpha$-hydroxylase (the enzyme that converts inactive vitamin D2 to its active D3 form) and vitamin D receptors in the brain. ${ }^{125,145,146}$ Interestingly, at the same time another study appeared ${ }^{147}$ in which vitamin D was reported to protect against cognitive decline in elderly participants. Possible mechanisms for the neuroprotective effects in PD, presumably impeding the loss of dopaminergic neurons, include antioxidative properties, modulation of intraneuronal calcium concentrations, especially in relation to mitochondria, and improved immune function. ${ }^{148}$ Since vitamin D deficiency is common in the general population, and frequent in the elderly, especially patients with neurodegenerative diseases, prudent optimization of vitamin D levels has been suggested to lower PD risk, delay cognitive loss, and assist musculoskeletal function. To achieve such levels, amounts of up to 8000 IU per day have been required, which necessitates careful monitoring, since this amount exceeds the 2000 IU recommended by Osteoporosis Canada and will also be higher than the anticipated new recommendation by the Institute of Medicine. Randomized clinical trials to confirm results of observational studies and delineate proper doses are needed.

\section{Conclusion}

"Mitochondrial therapy", both preventive and immediate, is a relatively new concept, and inroads have been significant, not only in neurologic disease but also in the intensive care unit, and in cardiology, renal, and other medical disciplines. While advances in the clinical management of PD with drugs have improved the quality of life in patients dramatically in terms of symptoms, there are no disease-modifying agents available. Recent work suggests that inflammation, oxidative, and nitrosative stress, accumulation of abnormally folded and/or aggregated proteins, and defects in the ubiquitin-proteasome system are central molecular events in the pathogenesis of familial and sporadic PD. The possible beneficial disease-modifying effects of CoQ10 and creatine are presented in the context of this current molecular model. In view of the rapid and encouraging recent work concerning omega-3 fatty acids and vitamin D, their supportive practical role in targeted pharmaconutritional therapy of PD deserves clinical consideration.

\section{Disclosure}

The author reports no conflict of interest in this work.

\section{References}

1. Dauer W, Przedborski S. Parkinson's disease: Mechanisms and models. Neuron. 2003;39:889-909.

2. Moore DJ, West AB, Dawson VL, Dawson TM. Molecular pathophysiology of Parkinson's disease. Annu Rev Neurosci. 2005;28:57-87.

3. Papapetropoulos S, Ellul J, Paschalis C, Athanassiadou A, Papadimitriou A, Papapetropoulos T. Clinical characteristics of the alpha-synuclein mutation (G209A)-associated Parkinson's disease in comparison with other forms of familial Parkinson's disease in Greece. Eur J Neurol. 2003;10:281.

4. Uversky VN. Alpha-synuclein misfolding and neurodegenerative diseases. Curr Protein Pept Sci. 2008;9:507-540.

5. Kamel F, Tanner C, Umbach D, et al. Pesticide exposure and self-reported Parkinson's disease in the agricultural health study. Am J Epidemiol. 2007; 165:364-374.

6. Hancock DB, Martin ER, Mayhew GM, et al. Pesticide exposure and risk of Parkinson's disease: A family-based case-control study. BMC Neurol. 2008;8:6.

7. Costello S, Cockburn M, Bronstein J, Zhang X, Ritz B. Parkinson's disease and residential exposure to maneb and paraquat from agricultural applications in the Central Valley of California. Am J Epidemiol. 2009;169:919-926.

8. Jankovic J. Searching for a relationship between manganese and welding and Parkinson's disease. Neurology. 2005;12:2021-2028.

9. Logroscino G, Gao X, Chen H, Wing A, Ascherio A. Dietary iron intake and risk of Parkinson's disease. Am J Epidemiol. 2008; 12:1381-1388. 
10. Tribl F, Asan E, Arzberger T, et al. Identification of L-ferritin in neuromelanin granules of the human substantia nigra: A targeted proteomics approach. Mol Cell Proteomics. 2009;8:1832.

11. Tribil F, Gerlach M, Marcus K, et al. "Subcellular proteomics" of neuromelanin granules isolated from the human brain. Mol Cell Proteomics. 2005;4:945-957.

12. Keeney PM, Xie J, Capaldi RA, Bennett JP Jr. Parkinson's disease brain mitochondrial complex I has oxidatively damaged subunits and is functionally impaired and misassembled. J Neurosci. 2006; 26:5256-5264.

13. Esteves AR, Domingues AF, Ferreira IL, et al. Mitochondrial function in Parkinson's disease cybrids containing an nt 2 neuron-like nuclear background. Mitochondrion. 2008;8:219-228.

14. Khusnutdinova E, Gilyazova I, Ruiz-Pesini E, et al. A mitochondrial etiology of neurodegenerative diseases: Evidence from Parkinson's disease. Ann NY Acad Sci. 2008;1147:1-20.

15. Knott AB, Bossy-Wetzel E. Impairing the mitochondrial fission and fusion balance: A new mechanism of neurodegeneration. Ann NY Acad Sci. 2008;1147:283-292.

16. Mannella C. Functional implications. Ann N Y Acad Sci. 2008;1147: 147-179.

17. Henchcliffe C, Shungu DC, Mao X, et al. Multinuclear magnetic resonance spectroscopy for in vivo assessment of mitochondrial dysfunction in Parkinson's disease. Ann N Y Acad Sci. 2008;1147:206-220.

18. Whitton PS. Inflammation as a causative factor in the aetiology of Parkinson's disease. Br J Pharm. 2007;50:963-976.

19. Chen H, O'Reilly RJ, Schwarzschild MA, Ascherio A. Peripheral inflammatory biomarkers and risk of Parkinson's disease. Am J Epidemiol. 2008;167:90-95.

20. Smith PF. Inflammation in Parkinson's disease: An update. Curr Opin Invest Drug. 2008;9:478-484.

21. Monahan AJ, Warren M, Carvey PM. Neuroinflammation and peripheral immune infiltration in Parkinson's disease: An autoimmune hypothesis Cell Transplant. 2008;4:363-372.

22. Klegeris A, McGeer EG, McGeer P. Therapeutic approaches to inflammation in neurodegenerative disease. Curr Opin Neurol. 2007; 20:351-357.

23. Wu XF, Block ML, Zhang W, et al. The role of microglia in paraquat-induced dopaminergic neurotoxicity. Antioxid Redox Signal. 2005;7:654-661.

24. Anderson JP, Walker DE, Goldstein JM, et al. Phosphorylation of Ser-129 is the dominant pathological modification of alpha-synuclein in familial and sporadic Lewy body disease. J Biol Chem. 2006 281:29739-29752

25. Smith RA, Adlam VJ, Blaikie FH, et al. Mitochondria-targeted antioxidants in the treatment of disease. Ann N Y Acad Sci. 2008;1147: 105-111.

26. Bean BP. The action potential in mammalian central neurons. Nat Rev Neurosci. 2007;8:451-465.

27. Chan CS, Guzman JN, Ilijic E, et al. 'Rejuvenation' protects neurons in mouse models of Parkinson's disease. Nature. 2007;447: 1081-1086.

28. Schwartz A, Ciechanover A. Targeting proteins for destruction by the ubiquitin system: Implications for human pathobiology. Annu Rev Pharmacol Toxicol. 2009;49:73-96.

29. Lee JT, Wheeler TC, Li L, Chin LS. Ubiquitination of $\alpha$-synuclein by Siah-1 promotes $\alpha$-synuclein aggregation and apoptotic cell death. Hum Mol Genet. 2008;17:906-917.

30. Sullivan PG, Dragicevic NB, Deng J-H, et al. Proteasome inhibition alters neural mitochondrial homeostasis and mitochondria turnover. J Biol Chem. 2004;279:20699-20707.

31. McGuire DM, Gross MD, Van Pilsum JF, Towle HC. Repression of L-arginine:glycine amidinotransferase synthesis by creatine at a pretranslational level. J Biol Chem. 1984;259:12034-12038.

32. Da Silva RP, Nissim I, Brosnan ME, Brosnan JT. Creatine synthesis Hepatic metabolism of guanidinoacetate and creatine in the rat in vitro and in vivo. Am J Physiol Endocrinol Metab. 2009;296:E256-E261.
33. Brosnan JT, Wijekoon EP, Warford-Woolgar L, et al. Creatine synthesis is a major metabolic process in neonatal piglets and has important implications for amino acid metabolism and methyl balance. J Nutr. 2009;139:1292-1297.

34. Rawson ES, Volek JS. Effects of creatine supplementation and resistance training on muscle strength and weightlifting performance. J Strength Cond Res. 2003;4:822-831.

35. Deldicque L, Atherton P, Patel R, et al. Effects of resistance exercise with and without creatine supplementation on gene expression and cell signaling in human skeletal muscle. J Appl Physiol. 2008; 2:371-378.

36. Cooke MB, Rybalka E, Williams AD, Cribb PJ, Hayes AJ. Creatine supplementation enhances muscle force recovery after eccentricallyinduced muscle damage in healthy individuals. Int Soc Sports Nutr. 2009;6:13.

37. Dolder M, Walzel B, Speer O, Schlattner U, Wallimann T. Inhibition of the mitochondrial permeability transition by creatine kinase substrates. Requirement for microcompartmentation. J Biol Chem. 2003;278:17760-17766.

38. Tarnopolsky MA, Beal MF. Potential for creatine and other therapies targeting cellular energy dysfunction in neurological disorders. Ann Neurol. 2001;49:561-574

39. Dai W, Vinnakota S, Qian X, Kunze DL, Sarkar HK. Molecular characterization of the human CRT-1 creatine transporter expressed in Xenopus oocytes. Arch Biochem Biophys. 1999;361:75-84.

40. Walter MC, Lochmuller H, Reilich P, et al. Creatine monohydrate in muscular dystrophies: A double-blind, placebo-controlled clinical study. Neurology. 2000;54:1848-1850.

41. Tarnopolsky M, Martin J. Creatine monohydrate increases strength in patients with neuromuscular disease. Neurology. 1999;52:854-857.

42. Andrews R, Greenhaff P, Curtis S, Perry A, Cowley AJ. The effect of dietary creatine supplementation on skeletal muscle metabolism in congestive heart failure. Eur Heart J. 1998;19:617-622.

43. Broqvist M, Arnqvist H, Dahlstrom U, Larsson J, Nylander E, Permert J. Nutritional assessment and muscle energy metabolism in severe chronic congestive heart failure - effects of long-term dietary supplementation. Eur Heart J. 1994;15:1641-1650.

44. Gotshalk LA, Volek JS, Staron RS, Denegar CR, Hagerman FC, Kraemer WJ. Creatine supplementation improves muscular performance in older men. Med Sci Sports Exerc. 2002;34:537-543.

45. Candow DG, Chilibeck PD, Chad KE, Chrusch MJ, Davison KS, Burke DG. Effect of ceasing creatine supplementation while maintaining resistance training in older men. J Aging Phys Act. 2004; 12:219-231.

46. Johnston APW, Burke DG, MacNeil LG, Candow DG. Effect of creatine supplementation during cast-induced immobilization on the preservation of muscle mass, strength, and endurance. J Strength Cond Res. 2009;23:116-120.

47. Battini R, Leuzzi V, Carducci C, et al. Creatine depletion in a new case with AGAT deficiency: Clinical and genetic study in a large pedigree. Molec Genet Metab. 2002;77:326-331.

48. Schulze A. Creatine deficiency syndromes. Mol Cell Biochem. 2003;244:143-150.

49. Rae C, Digney AL, McEwan SR, Bates TC. Oral creatine monohydrate supplementation improves brain performance: A doubleblind, placebo-controlled, cross-over trial. Proc Biol Sci. 2003;270: 2147-2150.

50. McMorris T, Harris RC, Swain J, et al. Effect of creatine supplementation and sleep deprivation, with mild exercise, on cognitive and psychomotor performance, mood state, and plasma concentrations of catecholamines and cortisol. Psychopharmacology (Berl). 2006;185:93-103.

51. McMorris T, Mielcarz G, Harris RC, Swain JP, Howard A. Creatine supplementation and cognitive performance in elderly individuals. Neuropsychol Dev Cogn B Aging Neuropsychol Cogn. 2007;14:517-528.

52. Rabchevsky AG, Sullivan PG, Fugaccia I, Scheff SW. Creatine diet supplement for spinal cord injury: Influences on functional recovery and tissue sparing in rats. J Neurotrauma. 2003;20:659-669. 
53. Hausmann ON, Fouad K, Wallimann T, Schwab ME. Protective effects of oral creatine supplementation on spinal cord injury in rats. Spinal Cord. 2002:40:449-456.

54. Sullivan PG, Geiger JD, Mattson MP, Scheff SW. Dietary supplement creatine protects against traumatic brain injury. Ann Neurol. 2000;48:723-729.

55. Adcock KH, Nedelcu J, Loenneker T, Martin E, Willimann T, Wagner BP. Neuroprotection of creatine supplementation in neonatal rats with transient cerebral hypoxia-ischemia. Dev Neurosci. 2002;24:382-388.

56. Zhu S, Li M, Figueroa BE, et al. Prophylactic creatine administration mediates neuroprotection in cerebral ischemia in mice. $J$ Neurosci. 2004;24:5909-5912.

57. Prass K, Royl G, Lindauer U, et al. Improved reperfusion and neuroprotection by creatine in a mouse model of stroke. J Cereb Blood Flow Metab. 2007;27:452-459.

58. Chaturvedi RK, Beal MF. Mitochondrial approaches for neuroprotection. Ann NY Acad Sci. 2008;1147:395-412.

59. Ikeda K, Iwasaki Y, Kinoshita M. Oral administration of creatine monohydrate retards progression of motor neuron disease in the wobbler mouse. Amyotroph Lateral Scler Other Motor Neuron Disord. 2000;1:207-212.

60. Dedeoglu A, Kubilus JK, Yang L, et al. Creatine therapy provides neuroprotection after onset of clinical symptoms in Huntington's disease transgenic mice. J Neurochem. 2008;85:1359-1367.

61. Ryu H, Rosas HD, Hersch SM, Ferrante RJ. The therapeutic role of creatine in Huntington's disease. Pharmacol Ther. 2005;108:193-207.

62. Hersch SM, Gevorkian S, Marder K, et al. Creatine in Huntington disease is safe, tolerable, bioavailable in brain and reduces serum $9 \mathrm{OH} 2 \mathrm{dG}$. Neurology. 2006;66:250-262.

63. Matthews RT, Ferrante RJ, Klivenyi P, et al. Creatine and cyclocreatine attenuate MPTP neurotoxicity. Exp Neurol. 1999;157:142-149.

64. Lawler JM, Barnes WS, Wu G, Song W, Demaree S. Direct antioxidant properties of creatine. Biochem Biophys Res Commun. 2002;290:47-52.

65. Anderson JK. Oxidative stress in neurodegeneration: Cause or consequence? Nat Rev Neurosci. 2004;5:S18-S25.

66. Speer O, Back N, Buerklen T, et al. Octameric mitochondrial creatine kinase induces and stabilizes contact sites between the inner and outer membrane. Biochem J. 2005;85:445-450.

67. Schlattner U, Tokarska-Schlattner M, Wallimann T. Mitochondrial creatine kinase in human health and disease. Biochim Biophys Acta. 2006;1762:164-180.

68. Elmore S. Apoptosis. A review of programmed cell death. Toxicol Pathol. 2007;35:495-516.

69. Trisciuoglio L, Emilio Bianchi ME. Several nuclear events during apoptosis depend on caspase-3 activation but do not constitute a common pathway. PLOS ONE. 2009;4:e6234.

70. Korge P, Byrd SK, Campbell KB. Functional coupling between sarcoplasmic reticulum-bound creatine kinase and $\mathrm{Ca}(2+)$-ATPase. Eur $J$ Biochem. 1993;3:973-980.

71. Klivenyi P, Calingasan NY, Starkov A, et al. Neuroprotective mechanisms of creatine occur in the absence of mitochondrial creatine kinase. Neurobiol Dis. 2004;15:610-617.

72. NINDS NET-PD Investigators. A randomized, double-blind, futility clinical trial of creatine and minocycline in early Parkinson disease. Neurology. 2006;66:664-671.

73. The Parkinson Study Group. Effects of tocopherol and deprenyl on the progression of disability in early Parkinson's disease. $N$ Engl J Med. 1993;28:176-183.

74. NIH Announces Phase III Clinical Trial of Creatine for Parkinson's Disease; 2007. Available from: http://www.ninds.nih.gov/news_and_events/ news_articles/pressrelease_creatine_03222007.htm. Accessed May 14, 2010.

75. Couzin J. Clinical research. Testing a novel strategy against Parkinson's disease. Science. 2007;315:1778.
76. Hass CJ, Collins MA, Juncos JL. Resistance training with creatine monohydrate improve upper-body strength in patients with Parkinson disease: A randomized trial. Neurorehabil Neural Repair. 2007; 21: 107-115.

77. Bliznakov EG, Wilkins DJ. Biochemical and clinical consequences of inhibiting coenzyme Q 10 biosynthesis by lipid-lowering HMG- CoA reductase inhibitors (statins): A critical overview. Adv Therap. 1998; $15: 213-228$

78. Kones R. Ubiquinone - pathophysiology and present role in heart disease. Medical Nutrition Matters. (American Dietetic Association Medical Nutrition Practice Group). 2009;29:5-18.

79. Navas P, Villalba JM. Regulation of ceramide signaling by plasma membrane coenzyme Q reductases. Methods Enzymol. 2004;378: 200-206.

80. Stocker R, Bowry VW, Frei B. Ubiquinol-10 protects human low density lipoprotein more efficiently against lipid peroxidation than does alpha-tocopherol. Proc Natl Acad Sci U S A. 1991;88: $1646-1650$

81. Schapira AH. Mitochondrial disease. Lancet. 2006;368:70-82.

82. Prezedborski S, Jackson-Lewis V. Mechanisms of MPTP toxicity. Mov Disord. 1998;13 Suppl 1:35-38.

83. Jenner P. Parkinson's disease, pesticides and mitochondrial dysfunction. Trends Neurosci. 2001;24:245-247.

84. Gao HM, Hong JS, Zhang W, Liu B. Distinct role of microglia in rotenone-induced degeneration of dopaminergic neurons. $J$ Neurosci. 2002;22:782-790.

85. Sherer TB, Betarbet R, Greenamyre JT. Environment, mitochondria, and Parkinson's disease. Neuroscientist. 2002;8:192-197.

86. Haas RH, Nasirian F, Nakano K, et al. Low platelet mitochondrial complex I and complex II/III activity in early untreated Parkinson's disease. Ann Neurol. 1995;37:714-722.

87. Schapira AH, Mann VM, Cooper JM, et al. Anatomic disease specificity of NADH CoQ1 reductase complex I deficiency in Parkinson's disease. J Neurochem. 1990;5:2142-2145.

88. Manfredi G. mtDNA clock runs out for dopaminergic neurons. Nat Genet. 2006;38:507-508.

89. Shults CW, Haas RH, Passov D, Beal MF. Coenzyme Q10 levels correlate with the activities of complexes I and II/III in mitochondria from parkinsonian and nonparkinsonian subjects. Ann Neurol. 1997; 42:261-264.

90. Beal MF, Matthews RT, Tieleman A, Shults CW. Coenzyme Q10 attenuates the 1-methyl-4-phenyl-1,2,3,6 tetrahydropyridine (MPTP) induced loss of striatal dopamine and dopaminergic axons in aged mice. Brain Res. 1998;783:109-114.

91. Favit A, Nicoletti F, Scapagnini U, Canonico PL. Ubiquinone protects cultured neurons against spontaneous and excitotoxin-induced degeneration. J Cereb Blood Flow Metab. 1992;12:638-645.

92. Beal MF, Henshaw DR, Jenkins BG, Rosen BR, Schulz JB. Coenzyme Q10 and nicotinamide block striatal lesions produced by the mitochondrial toxin malonate. Ann Neurol. 1994;36:882-888.

93. Moon Y, Lee KH, Park J-H, Geum D, Kim K. Mitochondrial membrane depolarization and the selective death of dopaminergic neurons by rotenone: Protective effect of coenzyme Q10. J Neurochem. 2005; 93:1199-1208.

94. Menke T, Gille G, Reber F, et al. Coenzyme Q10 reduces the toxicity of rotenone in neuronal cultures by preserving the mitochondrial membrane potential. Biofactors. 2003;18:65-72.

95. Horvath TL, Diano S, Leranth C, et al. Coenzyme Q induces nigral mitochondrial uncoupling and prevents dopamine cell loss in a primate model of Parkinson's disease. Endocrinology. 2003;44: 2757-2760.

96. Rango M, Bonifati C, Bresolin N. Parkinson's disease and brain mitochondrial dysfunction: A functional phosphorus magnetic resonance spectroscopy study. J Cereb Blood Flow Metab. 2006;26: 283-290. 
97. Hattingen E, Magerkurth J, Pilatus U, et al. Phosphorus and proton magnetic resonance spectroscopy demonstrates mitochondrial dysfunction in early and advanced Parkinson's disease. Brain. 2009; 132:3285-297.

98. Shults CW, Beal MF, Fontaine D, Nakano K, Haas RH. Absorption, tolerability, and effects on mitochondrial activity of oral coenzyme Q10 in Parkinsonian patients. Neurology. 1998;50:793-795.

99. Shults CW, Oakes D, Kieburtz K, et al; Parkinson Study Group. Effects of coenzyme Q10 in early Parkinson disease: Evidence for slowing of the functional decline, Phase II. Arch Neurol. 2002;59: 1541-1550.

100. NINDS NET-PD Investigators. A randomized clinical trial of coenzyme Q10 and GPI-1485 in early Parkinson disease. Neurology. 2007; 68:20-28.

101. Effects of Coenzyme Q10 (CoQ) in Parkinson Disease (QE3). Available from: http://clinicaltrials.gov/ct2/show/NCT00740714?term $=\mathrm{QE} 3+\mathrm{P}$ arkinson's\&rank=1. Accessed May 14, 2010.

102. Seitz G, Gebhardt S, Beck JF, et al. Ascorbic acid stimulates DOPA synthesis and tyrosine hydroxylase gene expression in the human neuroblastoma cell line SK-N-SH. Neurosci Lett. 1998;1: $33-36$.

103. Carrière I, Delcourt C, Lacroux A, Gerber M; POLANUT Study Group. Nutrient intake in an elderly population in southern France (POLANUT): Deficiency in some vitamins, minerals and omega-3 PUFA. Int J Vitam Nutr Res. 2007;77:57-65.

104. Nurk E, Drevon CA, Refsum H, et al. Cognitive performance among the elderly and dietary fish intake: The Hordaland Health Study. Am J Clin Nutr. 2007;86:1470-1478.

105. Dullemeijer C, Durga J, Brouwer IA, et al. n-3 Fatty acid proportions in plasma and cognitive performance in older adults. Am J Clin Nutr. 2007;86:1479-1485.

106. Rosenberg IH. Rethinking brain food. Am J Clin Nutr. 2007;86: $1259-1260$

107. Cole GM, Ma Q-L, Frautschy SA. Omega-3 fatty acids and dementia Prostaglandins Leukot Essent Fatty Acids. 2009;1:213-221.

108. de Lau LM, Bornebroek M, Witteman JC, Hofman A, Koudstaal PJ, Breteler MM. Dietary fatty acids and the risk of Parkinson disease: The Rotterdam study. Neurology. 2005;12:2040-2045.

109. Chen H, Zhang SM, Hernan MA, Willett WC, Ascherio A. Dietary intakes of fat and risk of Parkinson's disease. Am J Epidemiol. 2003;11:1007-1014.

110. Gao X, Chen H, Fung TT, et al. Prospective study of dietary pattern and risk of Parkinson disease. Am J Clin Nutr. 2007;6: 1486-1494.

111. Samadi P, Grégoire L, Rouillard C, Bédard PJ, Di Paolo T, Lévesque D. Docosahexaenoic acid reduces levodopa-induced dyskinesias in 1-methyl-4-phenyl-1,2,3,6-tetrahydropyridine monkeys. Ann Neurol. 2006;59:282-288.

112. Bousquet M, Saint-Pierre M, Julien C, Salem NJ, Cicchetti F, Calon F. Beneficial effects of dietary omega-3 polyunsaturated fatty acid on toxin-induced neuronal degeneration in an animal model of Parkinson's disease. FASEB J. 2008;22:1213-1225.

113. Calon F, Cicchetti F. Can we prevent Parkinson's disease with n-3 polyunsaturated fatty acids? Future Lipidol. 2008;2:133-137.

114. Suzuki H, Manabe S, Wada O, Crawford MA. Rapid incorporation of docosahexaenoic acid from dietary sources into brain microsomal, synaptosomal and mitochondrial membranes in adult mice. Int JVitam Nutr Res. 1997;67:272-278.

115. Mandavilli BS, Ali SF, Van Houten B. DNA damage in brain mitochondria caused by aging and MPTP treatment. Brain Res. 2000; $885: 45-52$

116. Treen M, Uauy RD, Jameson DM, Thomas VL, Hoffman DR. Effect of docosahexaenoic acid on membrane fluidity and function in intact cultured Y-79 retinoblastoma cells. Arch Biochem Biophys. $1992 ; 294: 564-570$
117. McNamara RK, Ostrander M, Abplanalp W, Richtand NM, Benoit SC, Clegg DJ. Modulation of phosphoinositide-protein kinase C signal transduction by omega-3 fatty acids: Implications for the pathophysiology and treatment of recurrent neuropsychiatric illness. Prostaglandins Leukot Essent Fatty Acids. 2006;75:237-257.

118. Chan CS, Guzman JN, Ilijic E, et al. Rejuvenation protects neurons in mouse models of Parkinson's disease. Nature. 2007;447: 1081-1086.

119. Kim HY. Novel metabolism of docosahexaenoic acid in neural cells. J Biol Chem. 2007;282:18661-18665.

120. Calder PC. Immunomodulation by omega-3 fatty acids. Prostaglandins Leukot Essent Fatty Acids. 2007;77:327-335.

121. Massaro M, Scoditti E, Carluccio MA, De Caterina R. Basic mechanisms behind the effects of n-3 fatty acids on cardiovascular disease. Prostaglandins Leukot Essent Fatty Acids. 2008;79:109-115.

122. Bazan N. Fish oil protects against diseases like Parkinson's. Science Daily. Mar 20, 2009. Available at: http://www.sciencedaily.com/ releases/2009/04/090419133844.htm. Accessed May 14, 2010.

123. Brenna JT, Salem N, Sinclair AJ, Cunnane SC; for the International Society for the Study of Fatty Acids and Lipids, ISSFAL. $\alpha$-Linolenic acid supplementation and conversion to n-3 long-chain polyunsaturated fatty acids in humans. Prostaglandins Leukot Essent Fatty Acids. 2009;80:85-91.

124. Rapoport SI, Miki Igarashi M. Workshop on DHA as a Required Nutrient: Can the rat liver maintain normal brain DHA metabolism in the absence of dietary DHA? Prostaglandins Leukot Essent Fatty Acids. 2009;81:119-123.

125. Garcion E, Wion-Barbot N, Montero-Menei CN, Berger F, Wion D. New clues about vitamin D functions in the nervous system. Trends Endocrinol Metab. 2002;13:100-105.

126. Sato Y, Kikuyama M, Oizumi K. High prevalence of vitamin D deficiency and reduced bone mass in Parkinson's disease. Neurology. 1997;49:1273-1278.

127. Evatt ML, Delong MR, Khazai N, Rosen A, Triche S, Tangpricha V. Prevalence of vitamin D insufficiency in patients with Parkinson disease and Alzheimer disease. Arch Neurol. 2008;65:1348-1352.

128. Lee DM, Tajar A, Ulubaev A, et al. Association between 25-hydroxyvitamin D levels and cognitive performance in middle-aged and old European men. J Neurol Neurosurg Psychiatry. 2009; 80: 722-729.

129. Buell JS, Dawson-Hughes B, Scott TM, et al. 25-hydroxyvitamin D, dementia, and cerebrovascular pathology in elders receiving home services. Neurology. 2010;74:18-26.

130. Hughes TA, Ross HF, Mindham RHS, Spokes EGS. Mortality in Parkinson's disease and its association with dementia and depression. Acta Neurol Scand. 2004;110:118-123.

131. Petroni ML, Albani G, Bicchiega V, et al. Body composition in advanced-stage Parkinson's disease. Acta Diabetol. 2003;40 Suppl 1: $187-190$

132. Venning G. Recent developments in vitamin D deficiency and muscle weakness among elderly people. BMJ. 2005;330:524-526.

133. Francis RM, Anderson FH, Patel S, Sahota O, van Staa TP. Calcium and vitamin $\mathrm{D}$ in the prevention of osteoporotic fractures. QJM. 2006; 99:355-363.

134. Bischoff-Ferrari HA, Willett WC, Wong JB, et al. Prevention of nonvertebral fractures with oral vitamin $\mathrm{D}$ and dose dependency: A meta-analysis of randomized controlled trials. Arch Intern Med. 2009; 169:551-561.

135. Visser M, Deeg JH Dorly, Lips P. Low vitamin D and high parathyroid hormone levels as determinants of loss of muscle strength and muscle mass (sarcopenia): The Longitudinal Aging Study Amsterdam. J Clin Endocrinol Metab. 2003;88:5766-5772.

136. Wicherts IS, van Schoor NM, Boeke AJP, et al. Vitamin D status predicts physical performance and its decline in older persons. J Clin Endocrinol Metab. 2007;92:2058-2065. 
137. Shinchuk L, Holick MF. Vitamin D and rehabilitation: Improving functional outcomes. Nutr Clin Pract. 2007;22:297-304.

138. Glerup H, Mikkelsen K, Poulsen L, et al. Hypovitaminosis D myopathy without biochemical signs of osteomalacic bone involvement. Calcif Tissue Int. 2000;6:419-424.

139. Broe KE, Chen TC, Weinberg J, Bischoff-Ferrari HA, Holick MF, Kiel DP. A higher dose of vitamin D reduces the risk of falls in nursing home residents: A randomized, multiple-dose study. JAm Geriatr Soc. 2007;55:234-239.

140. Prince RL, Austin N, Devine A, Dick IM, Bruce D, Zhu K. Effects of ergocalciferol added to calcium on the risk of falls in elderly high-risk women. Arch Intern Med. 2008;168:103-108.

141. Mocanu V, Stitt PA, Costan AR, et al. Long-term effects of giving nursing home residents bread fortified with 125 micrograms (5000 IU) vitamin D3 per daily serving. Am J Clin Nutr. 2009;89:1132-1137.

142. Newmark HL, Newmark J. Vitamin D and Parkinson's disease: a hypothesis. Mov Disord. 2007;22(4):461-468.
143. Knekt P, Kilkkinen A, Rissanen H, Marniemi J, Sääsksjärvi K, Heliövaara M. Serum vitamin D and the risk of Parkinson disease. Arch Neurol. 2010;67(7):808-811.

144. Evatt ML. Beyond Vitamin Status Is There a Role for Vitamin D in Parkinson Disease? Arch Neurol. 2010;67(7):795-797.

145. Haussler MR, Haussler CA, Bartik L, et al. Vitamin D receptor: molecular signaling and actions of nutritional ligands in disease prevention. Nutr Rev. 2008;66(Suppl2):S98-S112.

146. Eyles DW, Smith S, Kinobe R, Hewison M, McGrath JJ. Distribution of the vitamin D receptor and 1 alpha-hydroxylase in human brain. J Chem Neuroanat. 2005;29(1):21-30.

147. Llewellyn DJ, Lang IA, Langa KM, et al. Vitamin D and risk of cognitive decline in elderly persons. Arch Int Med. 2010;170(13); 1135-1141.

148. Buell JS, Dawson-Hughes B. Vitamin D and neurocognitive dysfunction: preventing "D"ecline? Mol Aspects Med. 2008;29(6): 415-422.

\section{Publish your work in this journal}

Clinical Pharmacology: Advances and Applications is an international, peer-reviewed, open access journal publishing original research, reports, reviews and commentaries on all areas of drug experience in humans. The manuscript management system is completely online and includes a very quick and fair peer-review system, which is all easy to use.
Visit http://www.dovepress.com/testimonials.php to read real quotes from published authors. 